OPEN ACCESS

Edited by:

Adrian M. Shrader

University of Pretoria, South Africa

Reviewed by:

Angela Gaylard,

Angela Gaylard, South Africa

Simon Chamaillé-Jammes,

Centre National de la Recherche

Scientifique (CNRS), France

*Correspondence:

Robin Naidoo

robin.naidoo@wwfus.org

Specialty section:

This article was submitted to

Animal Conservation,

a section of the journal

Frontiers in Conservation Science

Received: 01 October 2021

Accepted: 19 January 2022

Published: 17 February 2022

Citation:

Naidoo R, Beytell P, Brennan A, Kilian W, McCulloch G, Stronza A,

Taylor $R$, Tsholofelo $C$ and Songhurst $A$ (2022) Challenges to Elephant Connectivity From Border

Fences in the World's Largest

Transfrontier Conservation Area.

Front. Conserv. Sci. 3:788133. doi: 10.3389/fcosc.2022.788133

\section{Challenges to Elephant Connectivity From Border Fences in the World's Largest Transfrontier Conservation Area}

\author{
Robin Naidoo ${ }^{*}$, Piet Beytell ${ }^{2}$, Angela Brennan ${ }^{1,3,4}$, Werner Kilian ${ }^{5}$, Graham McCulloch ${ }^{6,7,8}$, \\ Amanda Stronza ${ }^{6,7}$, Russell Taylor ${ }^{9}$, Chief Tsholofelo ${ }^{10}$ and Anna Songhurst ${ }^{6,7,8}$ \\ ${ }^{1}$ WWF-US, Washington, DC, United States, ${ }^{2}$ Ministry of Environment, Forestry and Tourism, Directorate of Scientific \\ Services, Windhoek, Namibia, ${ }^{3}$ Interdisciplinary Biodiversity Solutions Program, University of British Columbia, Vancouver, \\ BC, Canada, ${ }^{4}$ Institute for Environment, Resources and Sustainability, University of British Columbia, Vancouver, BC, \\ Canada, ${ }^{5}$ Etosha Ecological Institute, Okaukuejo, Namibia, ${ }^{6}$ Ecoexist Trust, Maun, Botswana, ${ }^{7}$ Applied Biodiversity Science \\ Program, Texas A\&M University, College Station, TX, United States, ${ }^{8}$ Department of Zoology, University of Oxford, Oxford, \\ United Kingdom, ${ }^{9}$ WWF in Namibia, Windhoek, Namibia, ${ }^{10}$ Department of Wildlife and National Parks, Maun, Botswana
}

To more effectively protect biodiversity and promote sustainable development, transfrontier conservation areas (TFCAs) aim to enhance wildlife flows across national borders. This is true of the world's largest terrestrial TFCA, the Kavango-Zambezi (KAZA), home to half of Africa's savannah elephants that move across five countries in a mixed-use landscape. We used GPS tracking data from >100 collared elephants to evaluate how fences between Namibia and Botswana impact transboundary connectivity in KAZA. For female elephants these fences formed an impenetrable boundary, with no exchange between animals collared in Botswana and those collared in Namibia. Male elephants did cross border fences, although they remained a partial boundary, with 7 of 21 males accounting for most crossings. Our results suggest a review of fence alignment and de-commissioning of some fencing separating Namibia and Botswana, combined with increased support for fence-free interventions that reduce wildlife-livestock interactions, should be considered to meet the objectives of KAZA.

Keywords: transfrontier conservation, connectivity, elephant movement, movement barriers, corridors, fences, road ecology

\section{INTRODUCTION}

A fundamental goal of transfrontier conservation areas (TFCAs) is the enhanced flow of wildlife across national borders (Hanks, 2003). In a terrestrial context, TFCAs in various parts of the world aim to secure such flows for a number of ecological, cultural, and economic purposes, with the supposition that this will ultimately result in better prospects for conservation and sustainable development (Singh, 1997; Hanks, 2003; Liu et al., 2020). The popularity of the TFCA concept is reflected in the 227 transfrontier conservation areas across five continents designated as of 2007 (Lysenko et al., 2007), with southern Africa $(n=18)$ a particular hotspot. Recent analyses have identified numerous additional high priority transboundary areas for biodiversity conservation around the world, with varying degrees of establishment feasibility (Mason et al., 2020). 
In practice, there are a range of impediments to the free flow of wildlife and people across TFCAs. National sovereignty and the control of country borders remains an overriding national security priority, and political concerns can dominate the stated aims of TFCAs (Hanks, 2003). Joint management of natural resources can illuminate differences in management philosophies among nations that can be difficult to overcome (Mason et al., 2020). Concerns regarding criminal activities that may be facilitated by TFCAs, such as poaching, can result in bottlenecks to transboundary governance (Duffy, 2006). Finally, while states may benefit from joint management of natural resources that are shared among multiple countries, there can also be costs to such arrangements, such as an exportation of human-wildlife conflict across borders (Stoldt et al., 2020).

In addition to the socio-political barriers described above, physical barriers are also a direct challenge to transfrontier conservation (Liu et al., 2020). These may take the shape of walls or fences along national borders that restrict flows of wildlife and other ecosystem functions (Spierenburg and Wels, 2006). Natural barriers such as rivers and mountain ranges may also limit transfrontier connectivity and result in outcomes that are at odds with management visions of interconnectedness (Cozzi et al., 2013). Evaluating the impacts of these physical barriers on transfrontier connectivity is an important area of research that can illuminate whether political rhetoric regarding TFCAs are matched by on-the-ground outcomes, and if not, how management activities can help close this gap.

Here, we address a number of these issues in the KavangoZambezi Transfrontier Conservation Area (KAZA), the world's largest terrestrial TFCA (www.kavangozambezi.org). We use the TFCA's primary flagship species, the African savanna elephant (Loxodonta africana), as a key indicator species for landscape connectivity. Harnessing GPS satellite tracking collar data from $>100$ elephants, we assess the impact of fences between Namibia and Botswana, two of KAZA's five-member countries, on interconnectedness in the central part of the TFCA. These fences were initially erected to keep wildlife and livestock (particularly cattle) separated, in order to limit disease transmission. We compare crossing frequencies of fences to that of other potential linear barriers in our study area (roads and rivers), hypothesizing that fences would have the strongest negative impact on movement, with roads intermediate and rivers most permeable. We also expected that male elephants would cross all linear barriers more frequently than females. Our results have implications for the stated connectivity aims of KAZA, which potential decommissioning or re-alignment of fences could help address. They also add to transfrontier movements of elephants documented in other, unfenced parts of KAZA (e.g., Tshipa et al., 2017).

\section{MATERIALS AND METHODS \\ Study Area}

Our study area is a multi-country section of KAZA that encompasses roughly $175,000 \mathrm{~km}^{2}$ of Botswana and Namibia, the two countries in which our study of elephant movement ecology was initiated, as well as Angola and Zambia, where elephants in our dataset also ranged (Figure 1). The area encompasses a variety of natural habitat types, including seasonal savannahs, open woodland, bushland, rivers, and adjacent floodplains. Anthropogenic land use types include villages and urban areas, as well as croplands and grazing land.

The border fences between Botswana and Namibia were erected to guard against Contagious Bovine Pleuropneumonia transmission between wildlife and cattle, and cover sections of the western and northwestern part of Botswana's border with Namibia (east of the Kwando river, the Linyanti and Chobe rivers mark the unfenced border between the two countries). These fences include $\sim 200 \mathrm{~km}$ running north-south between Botswana and Namibia, including along Khaudum National Park in Namibia (erected in 1954), and $\sim 220 \mathrm{~km}$ running east-west toward the Kwando river, including along the southern edge of Bwabwata National Park in Namibia (erected in 1996). This latter fence was electrified in 1997 (Albertson, 1998), while in 2001, a $30 \mathrm{~km}$ section of the fence extending west from the Kwando river was decommissioned by mutual agreement between the two countries (Figure 1A). The current status of the NamibiaBotswana border fences is variable, although no parts of the fences remain electrified and there are intermittent breakages and gaps in numerous sections.

\section{Data Collection and Analysis}

From 2010 to the present we attached GPS satellite tracking collars to 105 elephants (41 adult males and 64 adult females) in the study area. Animals were darted from a helicopter and a GPS collar (one of Africa Wildlife Tracking, Televilt, or Vectronics) scheduled to record hourly GPS locations was placed around the neck. Collars were typically retrieved around 2 years after deployment. In the case of males, captured individuals were either solitary or from small, all-male herds ranging from 1 to 18 bulls, while for females the herd size associated with the collared individual ranged from 4 to 60 elephants. Details on dates and duration that each collar was active are provided in Supplementary Figure 1.

GPS layers for the various linear features in the study area were compiled from a variety of sources (see Brennan et al., 2020 for details). For all elephant GPS observations $(n=1,572,788)$ we calculated the distance to the nearest fence, river, and major road. We considered an "encounter" with one of these potential linear boundaries to have occurred when an animal ventured to any distance within $1 \mathrm{~km}$ of it. For each of these encounters, we recorded the straight-line distance in meters to the feature and whether the animal did or did not cross the fence, road, or river on its next hourly movement. For comparison we also recorded similar distances and crossing frequencies of male and female elephant encounters with the $30 \mathrm{~km}$ section of border between Namibia and Botswana that is unfenced (Figure 1A).

We modeled the probability of an elephant crossing a barrier (when within $1 \mathrm{~km}$ ) as a function of sex, distance to barrier (logtransformed), and barrier type, as well as interactions between sex and distance, and sex and barrier type. We used package brms in the R statistical environment (Burkner, 2017) to estimate this logistic regression model in a Bayesian framework, using weakly informative priors (Gelman et al., 2008), four chains 

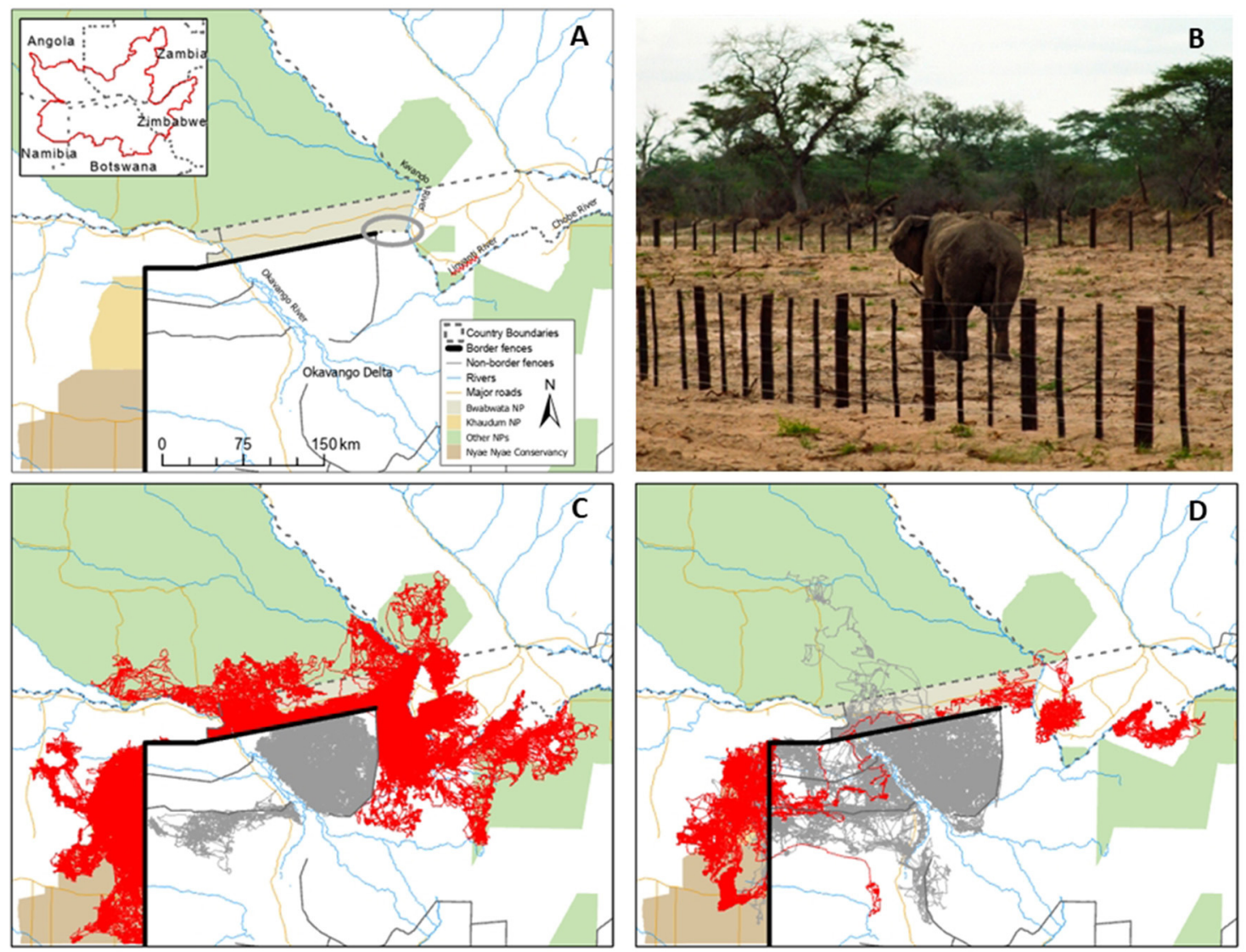

FIGURE 1 | Map of the Kavango-Zambezi study area, with an unfenced section of the border between Namibia and Botswana circled (A), illustrative photograph of a male elephant crossing a section of the Namibia-Botswana border fence (B), and maps of the movements of female (C) and male (D) elephants in the study area, with line color indicating those animals collared in Namibia (red) and Botswana (gray).

and 1,000 iterations for computation. We treated any regression coefficient whose 95\% credible intervals did not overlap with zero as showing strong evidence for a variable's effect, and used the R-hat statistic to assess parameter convergence, with 1.1 an established threshold below which convergence is satisfactory (Gelman et al., 2013).

\section{RESULTS}

\section{Fence Impacts}

Impacts of border fences varied by sex of elephant. Encounters with fences for collared female elephants and their associated breeding herds resulted in no recorded crossings ( 0 of 12,858 encounters within $1 \mathrm{~km}$; Figures 1C, 2). In contrast, collared male elephants did demonstrate crossing behavior, with border fences crossed $29.8 \%$ of the time when encountered within $25 \mathrm{~m}$, and declining steadily thereafter to $\sim 3.5 \%$ at a $1-\mathrm{km}$ encounter distance $(n=8,214$ total fence encounters within $1 \mathrm{~km}$; Figures 1D, 2A). This fence effect was separate from any independent or additional possible effects of the national border, since both females ( $n=15$ individuals) and males $(n=1$ individual) crossed a $30 \mathrm{~km}$ unfenced section of the NamibiaBotswana border at much higher rates than fenced sections (Figure 2A). Collectively, both sexes of elephants crossed the unfenced border section $\sim 47 \%$ of the time when within $25 \mathrm{~m}$, with crossing frequency declining thereafter to a level similar to that of males encountering fences at $600 \mathrm{~m}$. For both males and females fences therefore acted as barriers to movement, and in the case of females this effect was absolute. This result was also not due to males and females encountering different areas of fences that may have been in different conditions. On average males crossed fences in proportion to where they were encountered, and female fence encounters were highly spatially correlated with those of males, most of which occurred in five high-frequency clusters or hotspots (Figure 3).

In addition to spatial heterogeneity (Figure 3), fence-crossing behavior was also somewhat heterogenous among individual male elephants, with border crossing frequency, as a function of 1 -km encounters, varying from 0 to $29 \%$ with a mean of $11.5 \%$ (Supplementary Table 1). Three males never crossed a fence, and after accounting for the spatial location of crossings, there was strong evidence that two others had crossing frequencies that 

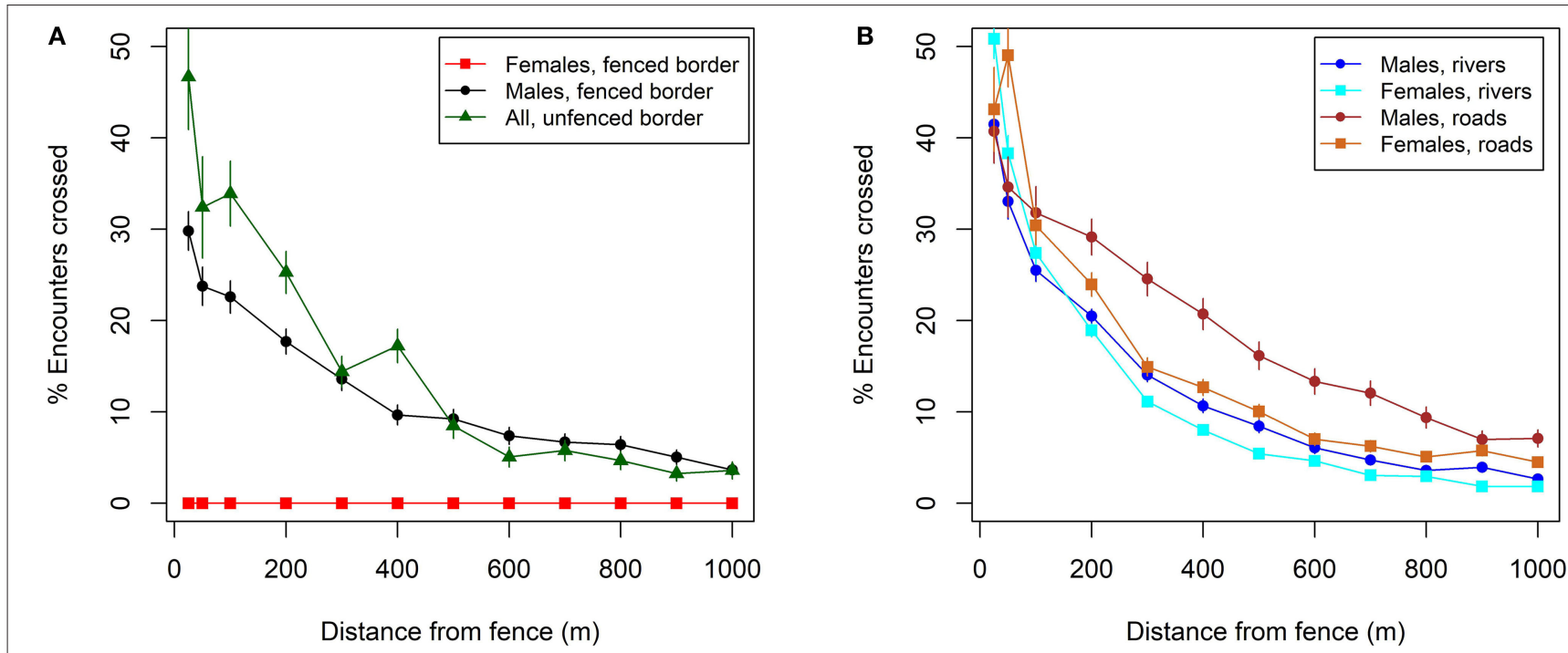

FIGURE 2 | (A) Percentage of times that a Namibia-Botswana border fence was crossed during an elephant's next hourly move, as a function of distance to fence at previous time step. Red = females, black = males, green = crossings (both male and female) of an unfenced section of the Namibia-Botswana border. (B)

Percentage of times that roads and rivers were crossed during an elephant's next hourly move, as a function of encounter distance to barrier at the previous time step. In both cases, distances to barriers were binned into 50, 100-m, and then every 200-m classes, and the mean and Bernoulli-trial standard deviation of fence crossing percentages were plotted.
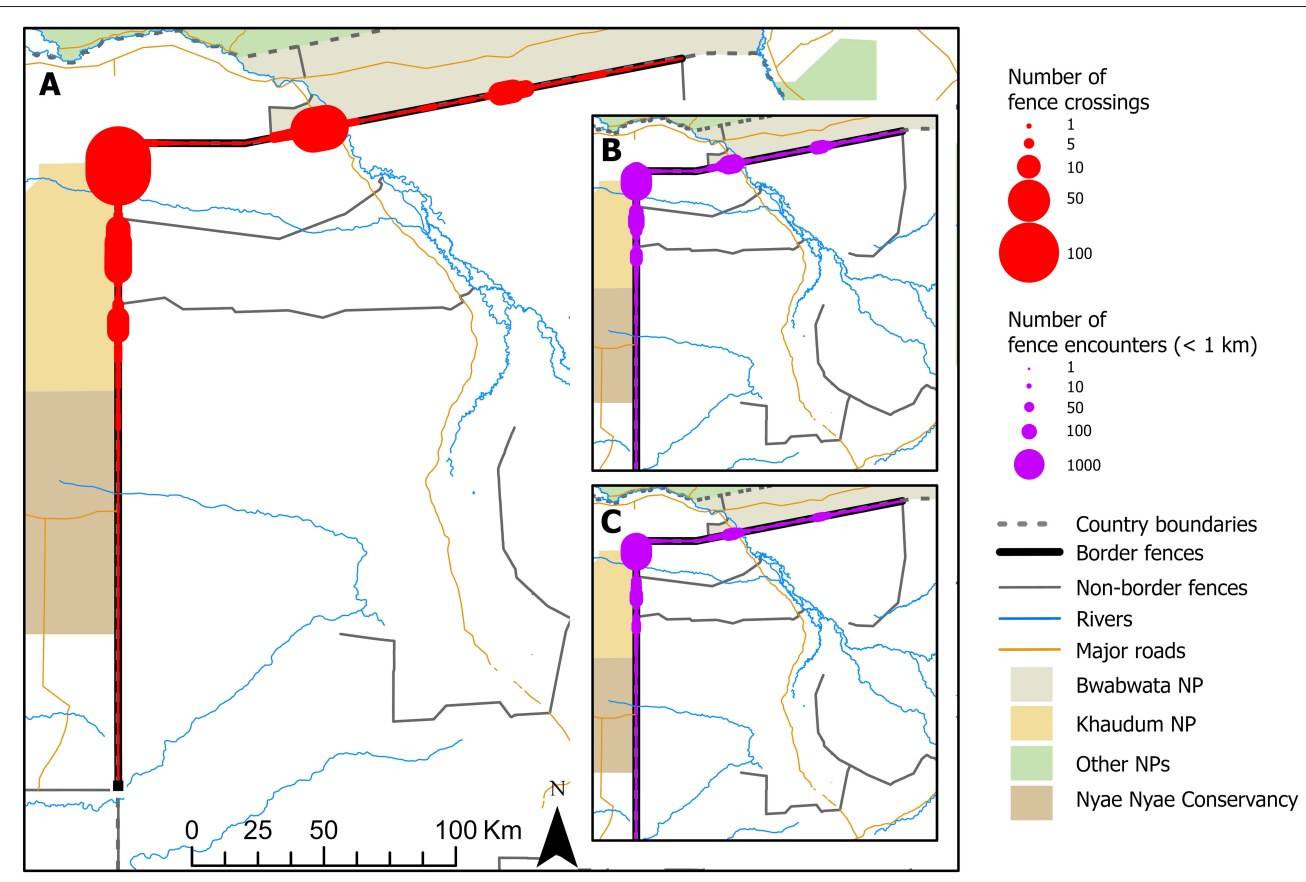

FIGURE 3 | (A) Spatial frequency of Namibia-Botswana border fence crossings by male elephants. Five distinct crossing "hotspots" are visible, with the highest number of $1 \mathrm{~km}$ fence encounters by both females (B) and males (C) also largely occurring in these same areas.

were lower than average ( 2 and $7 \%$, respectively). At the other end of the scale, there was strong evidence that four males crossed at frequencies greater than the average, ranging from 19 to $29 \%$.

\section{Road and River Impacts}

Rivers also acted as semi-permeable barriers to movement for both male and female elephants, although they were 
crossed more frequently than fences were (Figure 2B and Supplementary Table 2). Female elephants crossed rivers 2,830 times out of 27,891 encounters occurring within $1 \mathrm{~km}(10.1 \%)$, while males crossed 2,517 times out of 17,377 1-km encounters (14.5\%). Roads were even more permeable, with a higher percentage of crossings for both females $(15.3 \%$; 2,153 out of $14,006)$ and males $(25.8 \% ; 1,596$ out of 6,189$)$. Unlike both fences and rivers, there was no strong evidence for differences between road crossings and crossings of the unfenced border gap (Supplementary Table 2). Crossing frequencies for roads were also not different among males and females, unlike fences and rivers which were crossed more frequently by males. Furthermore, elephants were more likely to cross all types of barriers at smaller encounter distances (Supplementary Table 2), although there was no evidence that this effect varied among barrier type or sex. Male and female elephants had relatively similar hourly displacement distances: females $715 \mathrm{~m}$ (lower/upper 95\% quantiles 4-3,403) vs. males $861 \mathrm{~m}(3-5,450]$ ).

\section{DISCUSSION}

Fences along the border of Namibia and Botswana prevented collared female elephants that range in their vicinity from crossing from one country to the other. In contrast to the absolute effect for females, and as predicted, border fences were not an impermeable barrier for male elephants, although they nevertheless constrain movements to a degree. Taken together, border fences exert a strong negative effect on the movement of KAZA's flagship species, a result that has also been observed for other wildlife species in the TFCA (Cozzi et al., 2013; Naidoo et al., 2014; Brennan et al., 2020). In particular, utilization, dispersal, and/or recolonization of suitable habitat in KAZA that is currently devoid of elephants may proceed more quickly for males than for females given the difference in fence impacts (Druce et al., 2008). In contrast to border fences, rivers and especially roads did not appear to pose similar barriers to elephant movement (Cushman et al., 2010), with both males and females crossing these barriers either at slightly lower (rivers) or similar (roads) frequencies to an unfenced border section between Namibia and Botswana. In addition, rivers were crossed less frequently than roads by both sexes, which was contrary to our prediction that they would be the most permeable of all potential linear barriers encountered by elephants. In general, females were observed to cross all barrier types less frequently than males, possibly because females travel in breeding herds with their much-smaller offspring, who may be less willing or able to cross barriers, particularly fences that pose a height barrier to juvenile elephants, even when degraded. Male elephants in other parts of Africa also break fences at higher frequencies than females (e.g., Mutinda et al., 2014), suggesting this may also be occurring in our study area.

At present, the main linkage for elephants moving from northern Botswana into areas of suitable habitat in Namibia and Angola is the opening in the border fence starting at the Kwando river and extending some $30 \mathrm{~km}$ westwards (Figure 1A). One of the intentions of the KAZA TFCA is for elephants in densely populated northern Botswana (densities $\sim 2.8$ individuals $/ \mathrm{km}^{2}$ ) to move north through Namibia and eventually occupy more sparsely populated areas in southern Angola, where densities may be 30 times lower $\left(\sim 0.08 / \mathrm{km}^{2}\right.$; Schlossberg et al., 2018). Currently, however, the $\sim 200 \mathrm{~km}$ of fenced border between Bwabwata National Park in Namibia and northern Botswana, within the priority Kwando River "Wildlife Dispersal Area" (KAZA TFCA Secretariat, 2014), substantially restricts that potential.

Similarly, potential and possibly historical (Bollig and Olwage, 2016) large-scale elephant movements between the permanent waters of the Okavango Delta in Botswana and wet season habitats of the Nyae Nyae pans and Khaudum omurambas in Namibia are currently restricted by border fences. Reconnecting seasonal elephant migratory routes in this area will be even more challenging than in the north-south context described above. Human settlement and cattle populations along the Okavango river has resulted in few remaining access points to water (Songhurst et al., 2016), while the construction of artificial water points in Khaudum means the elephant population is now resident in and near the park year-round. Nevertheless, male elephants did regularly cross these fences, which are generally in poorer condition than those further north and had several crossing hotspots, and a review of fence alignments in relation to elephant and other wildlife movements would be a critical step toward this reconnection.

Despite the apparent conservation benefits, fence realignment or removal presents considerable political challenges. Veterinary cordon fences have been erected throughout southern Africa to separate wildlife and livestock so that the transmission of disease, particularly Foot-and-Mouth disease, is reduced (Taylor and Martin, 1987). Many fences have achieved this aim although consequent collapse of wildlife migrations in the region have been recorded (Gadd, 2012). Fence decommissioning can result in the recapitulation of at least some of these migrations (Bartlam-Brooks et al., 2011), however, for fence realignment or decommissioning to gain traction, alternate methods of reducing wildlife-cattle disease transmission in pastures and rangelands, such as non-geographic disease management that reduces the need for fences (Bing et al., 2017), will be necessary. Likewise, fence-free methods of limiting livestock movement into wildlife and high-end tourism areas need to be considered. Fortunately, strategies to address these concerns are currently in development and in principle show substantial promise, including approaches such as compartmentalization and commodity-based trade that are less tied to geographical restrictions (Thomson et al., 2013).

In addition, legitimate security concerns of nations that are considering fence realignment or decommissioning will need to be satisfied. Countries may view unfenced or unwalled borders as presenting opportunities for criminal elements to exploit, whether for poaching, smuggling, and/or trafficking of prohibited goods. These concerns are faced and addressed by all countries around the world in various ways (Vallet, 2014). The challenge is for member states of KAZA to develop approaches that alleviate their concerns while unlocking the wildlife movement potential upon which KAZA's vision of a connected social-ecological system and world class tourism destination is based.

Our results highlight both the transfrontier nature of wildlife movements in the Kavango-Zambezi region of southern Africa, but also the limits and barriers to such movement. Developing 
policies that enhance the former while easing the latter will ultimately determine the success of the KAZA TFCA.

\section{DATA AVAILABILITY STATEMENT}

The datasets presented in this article are not readily available because of the sensitivity of animal locations in areas of potential poaching. Requests to access the datasets should be directed to Robin Naidoo, robin.naidoo@wwfus.org.

\section{ETHICS STATEMENT}

The animal study was reviewed and approved by Ministry of Environment, Forestry and Tourism, Namibia.

\section{REFERENCES}

Albertson, A. (1998). Northern Botswana Veterinary Fences: Critical Ecological Impacts. Maun: Okavango People's Wildlife Trust.

Bartlam-Brooks, H. L. A., Bonyongo, M. C., and Harris, S. (2011). Will reconnecting ecosystems allow long-distance mammal migrations to resume? A case study of a zebra Equus burchelli migration in Botswana. Oryx 45, 210-216. doi: 10.1017/S0030605310000414

Bing, M., Marshall, C., and Masedi, M. (2017). Exploring Market Opportunities for Commodity-Based Trade (CBT) of Beef from Ngamiland, Botswana: Towards Harmonization of the Livestock and Wildlife Sectors. Ithaca, NY: Cornell University (AHEAD).

Bollig, M., and Olwage, E. (2016). The political ecology of hunting in Namibia's Kaokoveld: from Dorsland Trekkers' elephant hunts to trophyhunting in contemporary conservancies. J. Contemp. Afr. Stud. 34, 61-79. doi: 10.1080/02589001.2016.1182745

Brennan, A., Beytell, P., Aschenborn, O., Du Preez, P., Funston, P. J., Hanssen, L., et al. (2020). Characterizing multispecies connectivity across a transfrontier conservation landscape. J. Appl. Ecol. 57, 1700-1710. doi: 10.1111/1365-2664.13716

Burkner, P.-C. (2017). brms: an R package for Bayesian multilivel models using Stan. J. Stat. Softw. 80, 1-28. doi: 10.18637/jss.v080.101

Cozzi, G., Broekhuis, F., McNutt, J. W., and Schmid, B. (2013). Comparison of the effects of artificial and natural barriers on large African carnivores: implications for interspecific relationships and connectivity. J. Anim. Ecol. 82, 707-715. doi: 10.1111/1365-2656.12039

Cushman, S. A., Chase, M., and Griffin, C. (2010). "Mapping landscape resistance to identify corridors and barriers for elephant movement in southern Africa," inSpatial Complexity, Informatics, and Wildlife Conservation, eds S. A. Cushman and F. Huettmann (Tokyo: Springer), 349-367. doi: 10.1007/978-4-431-87771-4_19

Druce, H. C., Pretorius, K., and Slotow, R. (2008). The response of an elephant population to conservation area expansion: phinda private game reserve, South Africa. Biol. Conserv. 141, 3127-3138. doi: 10.1016/j.biocon.2008.09.024

Duffy, R. (2006). The potential and pitfalls of global environmental governance: the politics of transfrontier conservation areas in Southern Africa. Polit. Geogr. 25, 89-112. doi: 10.1016/j.polgeo.2005.08.001

Gadd, M. E. (2012). "Barriers, the beef industry, and unnatural selection: a review of the impact of veterinary fencing on mammals in southern Africa," in Fencing for Conservation, eds M. J. Somers and M. W. Hayward (New York, NY: Springer), 153-186. doi: 10.1007/978-1-4614-0902-1_9

Gelman, A., Carlin, J. B., Stern, H. S., Dunson, D. B., Vehtari, A., Rubin, D. B., et al. (2013). Bayesian Data Analysis, 3rd Edn. London: CRC Press. doi: $10.1201 / \mathrm{b} 16018$

Gelman, A., Jakulin, A., Pittau, M. G., and Su, Y.-S. (2008). A weakly informative default prior distribution for logistic and other regression models. Ann. Appl. Stat. 2, 1360-1383. doi: 10.1214/08-AOAS191

\section{AUTHOR CONTRIBUTIONS}

$\mathrm{RN}, \mathrm{RT}, \mathrm{AB}$, and ASo conceived the idea. $\mathrm{RN}$ and $\mathrm{AB}$ conducted the analysis and curated the field data. RN, $\mathrm{PB}, \mathrm{WK}, \mathrm{GM}, \mathrm{ASt}, \mathrm{CT}$, and ASo provided the data. RN wrote the initial manuscript draft. All authors contributed to the article, manuscript editing, revision, and approved the submitted version.

\section{SUPPLEMENTARY MATERIAL}

The Supplementary Material for this article can be found online at: https://www.frontiersin.org/articles/10.3389/fcosc. 2022.788133/full\#supplementary-material

Hanks, J. (2003). Transfrontier conservation areas (TFCAs) in Southern Africa. J. Sustain. For. 17, 127-148. doi: 10.1300/J091v17n,01_08

KAZA TFCA Secretariat (2014). Kavango-Zambezi Transfrontier Conservation Area: Master Integrated Development Plan, 2014-2019. Kasane: KAZA TFCA Secretariat.

Liu, J., Yong, D. L., Choi, C.-Y., and Gibson, L. (2020). Transboundary frontiers: an emerging priority for biodiversity conservation. Trends Ecol. Evol. 35, 679-690. doi: 10.1016/j.tree.2020.03.004

Lysenko, I., Besancon, C., and Savy, C. (2007). Global List of Transboundary Protected Areas. Cambridge, UK: UNEP-WCMC.

Mason, N., Ward, M., Watson, J. E. M., Venter, O., and Runting, R. K. (2020). Global opportunities and challenges for transboundary conservation. Nat. Ecol. Evol. 4, 694-701. doi: 10.1038/s41559-0201160-3

Mutinda, M., Chenge, G., Gakuya, F., Otiende, M., Omondi, P., Kasiki, S., et al. (2014). Detusking fence-breaker elephants as an approach in humanelephant conflict mitigation. PLoS ONE 9:e91749. doi: 10.1371/journal.pone. 0091749

Naidoo, R., Du Preez, P., Stuart-Hill, G., Beytell, P., and Taylor, R. (2014). Longrange migrations and dispersals of African buffalo (Syncerus caffer) in the Kavango-Zambezi Transfrontier Conservation area. Afr. J. Ecol. 52, 581-584. doi: 10.1111/aje.12163

Schlossberg, S., Chase, M. J., and Griffin, C. R. (2018). Poaching and human encroachment reverse recovery of African savannah elephants in south-east Angola despite 14 years of peace. PLoS ONE 13:e0193469. doi: 10.1371/journal.pone.0193469

Singh, J. (1997). "Transfrontier Conservation Areas (TFCAS) - creating opportunities for cooperation," in Blue Ridge Heritage Corridor: Celebrating Our Past, Creating Our Future, ed A. Consortium (Durham, NC: University of North Carolina Press), 72-76.

Songhurst, A., McCulloch, G., and Coulson, T. (2016). Finding pathways to human-elephant coexistence: a risky business. Oryx 50, 713-720. doi: 10.1017/S0030605315000344

Spierenburg, M., and Wels, H. (2006). "Securing space":mapping and fencing in transfrontier conservation in Southern Africa. Space Cult. 9, 294-312. doi: $10.1177 / 1206331206289018$

Stoldt, M., Gottert, T., Mann, C., and Zeller, U. (2020). Transfrontier conservation areas and human-wildlife conflict: the case of the Namibian component of the Kavango-Zambezi (KAZA) TFCA. Sci. Rep. 10:7964. doi: 10.1038/s41598-020-64537-9

Taylor, R. D., and Martin, R. B. (1987). Effects of veterinary fences on wildlife conservation in Zimbabwe. Environ. Manage. 11, 327-334. doi: $10.1007 / \mathrm{BF} 01867160$

Thomson, G. R., Penrith, M. L., Atkinson, M. W., et al. (2013). Balancing livestock production and wildlife conservation in and around Southern Africa’s transfrontier conservation areas. Transbound. Emerg. Dis. 60, 492-506. doi: 10.1111/tbed.12175 
Tshipa, A., Valls-Fox, H., Fritz, H., Fritz, H., Collins, K., Sebele, L., et al. (2017). Partial migration links local surface-water management to large-scale elephant conservation in the world's largest transfrontier conservation area. Biol. Conserv. 215, 46-50. doi: 10.1016/j.biocon.2017.09.003

Vallet, E. (2014). Borders, Fences, and Walls: State of Insecurity? London: Routledge.

Conflict of Interest: The authors declare that the research was conducted in the absence of any commercial or financial relationships that could be construed as a potential conflict of interest.

Publisher's Note: All claims expressed in this article are solely those of the authors and do not necessarily represent those of their affiliated organizations, or those of the publisher, the editors and the reviewers. Any product that may be evaluated in this article, or claim that may be made by its manufacturer, is not guaranteed or endorsed by the publisher.

Copyright (C) 2022 Naidoo, Beytell, Brennan, Kilian, McCulloch, Stronza, Taylor, Tsholofelo and Songhurst. This is an open-access article distributed under the terms of the Creative Commons Attribution License (CC BY). The use, distribution or reproduction in other forums is permitted, provided the original author(s) and the copyright owner(s) are credited and that the original publication in this journal is cited, in accordance with accepted academic practice. No use, distribution or reproduction is permitted which does not comply with these terms. 